\title{
Lowering the pump power requirement for squeezed light generation using a periodically poled crystal
}

\section{Andersen, Ulrik Lund; Buchhave, Preben}

Published in:

European Quantum Electronics Conference, 2003. EQEC '03.

Publication date:

2003

Document Version

Publisher's PDF, also known as Version of record

Link back to DTU Orbit

Citation (APA):

Andersen, U. L., \& Buchhave, P. (2003). Lowering the pump power requirement for squeezed light generation using a periodically poled crystal. In European Quantum Electronics Conference, 2003. EQEC '03. IEEE.

\section{General rights}

Copyright and moral rights for the publications made accessible in the public portal are retained by the authors and/or other copyright owners and it is a condition of accessing publications that users recognise and abide by the legal requirements associated with these rights.

- Users may download and print one copy of any publication from the public portal for the purpose of private study or research.

- You may not further distribute the material or use it for any profit-making activity or commercial gain

- You may freely distribute the URL identifying the publication in the public portal

If you believe that this document breaches copyright please contact us providing details, and we will remove access to the work immediately and investigate your claim. 


\title{
Lowering the pump power requirement for squeezed light generation using a periodically poled crystal
}

\author{
Ulrik L. Andersen and Preben Buchhave \\ The Optics Group, Department of Physics, Technical University of Denmark \\ DK-2800 Lyngby, Denmark \\ e-mail: pbu@ufisik.dtu.dk
}

The degree of squeezing in the frequency doubled beam from resonant second harmonic generation (SHG) [1] is known to depend critically on two parameters: The internal passive loss in the resonator and the effective nonlinear coefficient for the SHG-process. Contrary to the loss parameter, which is known to make irreparable damage to the squeezing, a weak nonlinearity may be compensated by the application of a stronger pump. This compensation may not always be desirable as high pump powers in second harmonic generation produce a squeezed beam with a brightness that might be undetectable and perhaps damaging for samples that possibly are going to be examined by the light. For these reasons, the aim is in general to apply materials with as high nonlinearities as possible, since it makes the squeezing production more flexible.

The experimental efforts leading to the observation of continuous wave bright squeezed light from an intra-cavity periodically poled KTP second harmonic generator are presented. These efforts include characterization of the classical as well as the quantum properties of the system.

The system comprises a stable Nd:YAG nonplanar ring laser, a mode cleaner for classical noise reduction, buildup cavity used for enhancing the nonlinear interaction process and a self-homodyne detection system. The classical conversion efficiency as well as the amount of generated frequency doubled power as a function of the infra-red laser power of the system were investigated. Stability of the green power was ensured by dynamical control of one of the cavity mirrors using a phase locking technique. Conversion efficiency of $48 \%$ was achieved with a pump power of only $100 \mathrm{~mW}$.

Owing to the nonlinear coupling in the crystal, fluctuations of the infra-red laser beam transfers to the green light. These excess fluctuations are detrimental to the production of squeezed light and therefore reduced employing a mode cleaner. After passing the mode cleaner the infra-red laser light is quantum noise limited at $6 \mathrm{MHz}$.

Finally, we measured the degree of noise suppression below the quantum noise limit in the generated frequency doubled green beam using a self-homodyne detection system. A squeezing of $13 \%$ was observed at relatively low pump power. Although modest, this degree of noise suppression is much higher than one would expect from a normal birefringence phase-matched KTP crystal under the same operating conditions. Using a rather simple theory [1], excellent agreement was found between theory and our experimental results

[1] R. Paschotta et al. Phys. Rev. L.ett. 72, 3807 (1994). 